\title{
A Comparative Study of Student Organizations in Mainland China and Hong Kong Universities - Based on the Perspective of Innovation and Entrepreneurship Associations
}

\author{
Baoshan $\mathrm{Yu}^{1}$ \\ ${ }^{1}$ Jinan University, Guangzhou, China \\ Correspondence: Wen Lixia, Lecturer, Jinan University, Guangzhou, Guangdong, China. Tel: \\ 86-0138-2309-4418. E-mail: shiqishidai1983@jnu.edu.cn
}

Received: May 2, 2018 Accepted: May 8, $2018 \quad$ Online Published: August 31, 2018

doi:10.5539/ass.v14n9p8 URL: https://doi.org/10.5539/ass.v14n9p8

The paper reported here is sponsored by Guangdong Provincial Planned Educational and Scientific Project, Project name: "Four Confidences in the Path, Theory, System, and Culture" and the Cultivation of Innovative and Entrepreneurial College Students, Project Grant No.:2018JKSJD82.

The research is also phased result by the specific project of the $21^{\text {st }}$ Teaching Reform and Research in Jinan University (non-Mainland Students), Project name: Construction and Application of Innovative and Entrepreneurial Training Platform for non-Mainland Students-A Case Study at International Business School, Project Grant No.: JG2018061.

\begin{abstract}
In order to thoroughly apply the spirit of $18^{\text {th }}$ National Congress of Communist Party of China, strengthening the work of youth under the new situation is the inner requirement of the Communist Youth League. Furthermore, it plays a needing role in doing the youth work under the new situation. As a bridge between college students and society, student organization is an important part of student affairs in universities. In addition, employing the advanced experience in organization management provides theoretical and practical significances to the work of the Communist Youth League in the new situation. Based on the student organization of Mainland and Hong Kong Universities, the project discusses the different performance of Mainland and Hong Kong Universities with the method of comparative study. From the view of student organizations of innovation and entrepreneurship, the project aims to offer the reference to student organizations in Mainland.
\end{abstract}

Keywords: college student, association, Hong Kong, enlightenment

\section{Introduction}

In recent years, mainland China attaches great importance to innovation and entrepreneurship of college students, and vigorously encourage college students to carry out entrepreneurial activities, but the famous innovative startups run by mainland college students are relatively rare, so we need to learn from advanced experience of Hong Kong universities in areas of management system, in order to promote innovative entrepreneurship work in Mainland Universities.

Currently Chinese college student community research, mainly around the college students, sports associations, bike community concept, and the development of the status quo and the emergence of problems. Xiao Rong did a preliminary research on the definition an initial to the definition of the concept of student community, and he divided into two categories of narrow and broad sense for our study of college laying for our research a theoretical basis. From a variety of angles, Li Dawei on the current development of college students in the status quo, the existing problems and countermeasures were discussed, and achieved some research results. Liao Lianghui and other comparative studies on the development history, current situation, management and construction of the students' associations in China and the United States, and the comparative study of the student associations of Hong Kong, Macao and Taiwan universities and the mainland community, trying to reveal different societies Environment, cultural differences, the similarities and differences between student associations, and to improve and improve the management system to provide a reference. 
Summing up the mentioned results, regarding the research community college students, the effect is obvious, research is quite good, relevant outcomes are already complete, but some new research communities also exist research vacuum. That the above results are mainly concentrated on the research of community domestic or foreign universities, comparative research on student organizations and universities in Hong Kong, Mainland comparative study are missed, Hong Kong slightly weak innovation and entrepreneurship classes and community health, you can see the author related results were published less, especially at the country and the government under increasing emphasis on innovation and entrepreneurship education background, it is necessary to carry out related research.

\section{Development of the Mainland and Hong Kong University Students' Association}

\subsection{General Situation of Mainland College Student Association}

Historical development of student organizations than later, the first student association in 1920 by the Peking University students in the summer of Deng and other established study of Marxist theory. Student Associations of Universities gone through two peak periods, before and after the first "54" campaign, the second is after the 1980s. Before and after "54" campaign, a time when all kinds of thoughts fierce collision period, literati Chester Exploring the death to save the road. Therefore, the establishment and participation in student organizations was mostly of social thought and discussion by revolutionary practitioner, a relatively strong political overtones. The late 1970s, along with the recovery of high-test system, a large number of aspiring young people to enter the university campus, student organizations then appeared in large numbers, until the mid-1980s, community heat reached its climax, community activities has almost become the main form of student extracurricular activities in active campus culture, and improving their comprehensive ability has played an important role. "According to statistics, in 1986, the number of Beijing, Wuhan, Anhui college students participating in community respectively accounted for $30 \%$ of the total number, $40 \%, 40 \%$ or more."

In the 1990s, with the gradual advance and the implementation of Quality Development Plan of Central Communist Youth League, the Ministry of Education, the National Education Federation of University Students, University Students' Association is developing rapidly, the number of community organizations, the type and number of members are developing fast. In 2002, in order to further implement the spirit of the Decision of the CPC Central Committee and the State Council on Deepening Educational Reform and Promoting Quality Education in an All-round Way the Central Committee of the Communist Youth League, the Ministry of Education and the National Federation of the Communist Party of China (CPC), meet the urgent need for economic and social development to develop human resources, especially young human resources, the full implemented the University Education services, to adapt to the majority of Youth Development, and met the aurgent need for employment and entrepreneurship, and in some colleges and universities nationwide to carry out "students quality Development plan" pilot work, and in full swing in 2003, the objective of significantly advancing The Rapid Development of College Students' Associations. According to a survey conducted by the Central Committee of the Communist Youth League and the China Youth Research Center in 2005, there are currently about 45,000 student associations in China, with an average of 20 colleges per university. $59.7 \%$ of the students involved in the school community, the number of communities involved in an average of 1.8.

Mainland university student community funding sources can be divided into three types: First, members of the community pay the membership fee, which are the basic funds for community activities and are the main means of funding the student associations in mainland China. The vast majority of student organizations only charge 10-30 yuan per person per year, the membership fee is relatively low, one-time charge of the basic fees can not meet and maintain the normal activities of the community. Second, the school special funds allocated. The funds are basically arranged by the Communist Youth League of colleges and universities, but due to the relatively tight funding of student activities in colleges and universities, and the large number of student associations, the allocation of funds will be leant towards those organizations run the Communist Youth League directly led, so the school allocated to The funding of the student community is also extremely limited. Third, the community sponsors. With the interaction between colleges and the community increasingly close, some student associations in carrying out activities, will seek and social enterprises and other units of cooperation in order to obtain sponsorship funds.

At present, China University Students' Association showed an potential of increase in the number, scale, improved management, the students gradually increased cohesion and influence the characteristics, but also exhibit many new situations and new trends, one is academic, scientific and technological nature comprehensive class associations, network associations increased, community activities and social, media contacts increased, increased inter-school, after-school activities, reflecting the innovative community development. On the other 
hand is the lack of scientific value-oriented, utilitarian activities blindness and more prominent; loose internal management, the lack of specification; lack of funds and the management and use of funds chaos; poor continuity of community, content and deep enough, repeat The establishment of more phenomena. In this regard, many colleges and universities in the Central Committee under the initiative to strengthen the work of students in the community at the same time, have set up student associations to achieve self-management of student associations, but the effect is still not ideal, can not fully adapt to the rapid development of student associations Claim.

\subsection{Before the Hong Kong College Student Association}

Hong Kong's educational background is different because of different historical backgrounds. Therefore, students' associations based on colleges and universities also show different characteristics. Organizational structure and operational mechanism with the Mainland Universities College Student Association of Hong Kong than the big difference, it is not primarily dependent on the self-activity of administrative appropriations, independent community organizations self-financing, with higher independence. But one thing is the same and the Mainland, Hong Kong Universities student activities is mainly dependent on the levels of student and community organizations. While many students in community colleges completely independently conduct formal operation, in practice, the Student Affairs Office Student Association still be some degree of external issues guidance, management and supervision, student organizations also increasing Student Affairs Office is responsible. Student Associations of University of Hong Kong are generally separate operations, a separate office to promote student government, campus cohabitation as the goal, actively involved in the internal affairs of the school, students promote awareness and participation in society, co-ordinate activities and student organizations, provide students the welfare, organized recreational activities. Foreign represents the students to express their views, in a statement, participation in social affairs. the kind of student societies quite a lot, mainly Astronomical Society, Magic Club, Lions Club of Castle Peak, Rotary Youth League, community service groups, learn to invest, trade Society, drama, singing contest Preparatory Committee, the campus radio station, student newspaper, radio arts groups, celebration of the Preparatory Committee, the Preparatory Committee orientation camp, Bridge Association, the Association of animation, and each country is to learn to stand hostel boarders would like.

College Student Association of Hong Kong generally produce through the campaign, but there are some ways to produce by the interview. Hong Kong university student representatives and the Director-General will establish, in accordance with some principles of the separation of powers established arbitration hearing. The community is an important part of the student union and accepts the delegates to lead. Representatives by the President, Vice President, and a number of the Standing Committee of the Secretariat composed of representatives from each faculty affiliated general, Sadang and associations affiliated units assigned, the number of places depending on their number of members, depending on where each community weigh heavily weight. Their important duty is to safeguard the interests of students, organized students to carry out activities. Hong Kong College student union both affiliated faculty, but also the affiliated associations. Graduate students with the Mainland will be different, affiliation Postgraduates Hong Kong will include various functional departments and graduate student associations affiliated, generally do not graduate faculty will, their activities tend to student organizations, the main activities carried out by the community. Hong Kong university student dormitory also has its own student union and community organizations, called Sadang Sadang boarders will or student. Affiliated associations are generally divided in accordance with the common sports, entertainment-loving style of established associations, federations according to some established local students, etc., with academic research academic community, religious communities, social, welfare, charitable organizations, Sadang community organizations. The election of student councils and community positions in Hong Kong is also known as "Shang Zhuang", "Zhuang" is the meaning of the cabinet. In order to help the student union to cope with the busy student work, the universities in Hong Kong have made a requirement that the main cadres, such as the main heads of the community, can apply for one year of school work and full-time student and community work. Students who work in the student union Generally, the flexibility of the school-based interest-free loan plus the flexibility of the credit system, which is to ensure the efficient operation of student organizations, students more extensive, more engaged in student work to promote their own team management skills, practical skills, interpersonal communication, improve the overall quality to create the conditions.

Sources of funding college student organization in Hong Kong, include the main contributions, social and alumni contributions paid by members, student organizations operating earnings and investment, the school and the SAR government funding and so on. Hong Kong Federation of some students as well as cultural, sports federation, according to the Society Council of Student Associations categories such settings, such communities 
need to be registered in the categories of community, before once again become the student union affiliated to become affiliated Of the student community, Shechang students will be able to apply for the use of school students will be the resources. School students and to affiliated societies can provide financial grants, activities, network services, interest-free loans. The student council will also review the qualifications and financial status of the association and the community, including the constitution, number of members, institutional setting, activity plan, effectiveness of the election results and the payment of the income and expenditure, the financial report, the use of student funding. Such as the Chinese University of Hong Kong Student Affairs in each semester provides a wide range of student activities fund for the school to apply for student groups, including student activity funding Alumni Association Student Activities Fund and the HSBC fund student activities. Student activities are funded by the student organizations of the Chinese University of Hong Kong (excluding the school community). The purpose of the subsidy is to support the student organizations to organize more meaningful extracurricular activities. The amount of subsidy depends on the meaning, size, nature and benefit , The degree of help to the development of the group and other factors may be, the group activities of the food expenditure will not be funded.

\section{The Comparison of Innovation and Entrepreneurial Associations Between the Mainland and HK's Universities}

In November 2014, according to the document about enhancing national college graduates' entrepreneurship in 2005 from the Ministry of Education, colleges and universities have to integrate theory with practice, innovation and entrepreneurship to organize students to participate in various competitions, business simulation practice Activities, make efforts to cultivate students' innovative spirit, entrepreneurial awareness and innovative entrepreneurial ability. There are Part innovation and entrepreneurship category Communities in Mainland and Hong Kong colleges and universities, Which were established time earlier, such as Tsinghua University students Entrepreneurs Association, founded in May 2004, through the game, forums, Salon, the association expand the quality of training camps, etc., universal business knowledge, explore entrepreneurial literacy method, providing consulting services to student entrepreneurs, investors and for the excellent team and project to build bridges, promote scientific and technological achievements. Hong Kong University of Science and Technology Innovation Center was established in 1999, by conducting entrepreneurship workshops, lectures, organizing entrepreneurship competition, to carry out composite entrepreneurship courses, student support entrepreneurship, to serve teachers and students.

In comparison, the innovation and entrepreneurial associations in HK's universities started early, developed rapidly, has been more mature, plus the status as an international financial center, after ten years of development, They have shown remarkable characteristics, and Has achieved remarkable results. Since the limited period of fadevelopment, there are still shortcomings in the system mode, effects and results.

\subsection{Comparison of Management Guiding Ideology}

Mainland and Hong Kong's community colleges and universities due to differences in educational background, educational philosophy and social management guiding ideology must also exist differences.

In 2016, the CYL Central Committee, the Ministry of Education, the National Federation recently issued "Interim Measures on Management of College Students' Associations" (hereinafter referred to as the "Rules"), the unified leadership of the Party Committee of University documentation requirements of our students community work, should strengthen and improve the work of student organizations, to implement the party's education policy, promote quality education an important part. In order to follow the principles of voluntariness, autonomy and spontaneousity, make use of the network technology and new media to carry out the theme, and it is healthy and beneficial and rich and colorful. under extracurricular activities online and offline, prosperity campus culture, cultivate students' sense of social responsibility, innovative spirit and practical ability to improve the overall quality of students, promote student growth and success. In the events, the "community organizing activities subject to the relevant rules and regulations Universities, and in accordance with the appropriate approval process can not be spread among students violate the Constitution, laws, regulations and policies of the Party's line, principles and statements wrong views, not to carry out its inconsistent with the purposes of the activity, not to carry out purely commercial activities. "Overall, community colleges and universities in the Mainland have unity guidance document, under the guidance of the Communist Youth League committees and universities, carry out related activities, in order to achieve" self-service, self-education Self-management "purposes.

Compared to the mainland, HK's universities Students' Association has embraced pragmatism, rationalism and a new humanism, Juche the university student associations, different, but invariably will integrate Eastern and 
Western cultures, has formed its own characteristics Holistic Education and education model, in the premise of freedom and democracy on their own learning, life and development. Hong Kong university student community is used in the school under the strict rules and regulations of the student self-management model, in the framework of the perfect system to give students enough freedom, let it decide the direction of development, the school does not impose intervention, the Hong Kong University Student Association Is the student union, to accept the unified management of the student union, are generally a separate operation to promote student autonomy, campus governance as the goal. Therefore, the Hong Kong community colleges and universities are more close to social organization, independent, community management also has a vocational, academic and other characteristics, College Students' Associations and similar Western countries, will hire some qualified staff to participate in community management, Student societies have basic support for their associated private or nonprofit organizations in society, and many have established long-term partnerships, and individual student societies or organizations have been registered as official social groups in government agencies.

\subsection{Compare the Degree of Social Functioning}

Some colleges and universities in Hong Kong have set up special educational institutions such as Hong Kong University of Science and Technology, Hong Kong Polytechnic University Enterprise Development Institute, Hong Kong Chinese University Entrepreneurship Research Center, Hong Kong University Technology Transfer Office, etc., assume the role of innovation and entrepreneurship education and tasks, these high degree of socialization of professional organizations has strengthened the connection between schools and business circles. Their establishment have directly promoted the emergence and development of students' entrepreneurial societies. Hong Kong Polytechnic University Institute for Enterprise is "shouldering the knowledge transfer and business incubation two task, provided an important platform for the academia and the business sector, to promote bilateral ties and close cooperation, mutual benefit. With expertise and resources, the University Institute for enterprise provides diversified services, both to support the development of public enterprises, but also help the business sector to develop innovative products to enhance their competitiveness in the international market. "

In these specialized entrepreneurship institutions, student entrepreneurship community can not only receive professional entrepreneurship education courses and guidance, but also with the social elite to communicate directly. For example, the "Friday Dreamers Workshop", organized by the Hong Kong University of Science and Technology's Center for Entrepreneurship, provides an informal platform for members of the community (students, business center staff, etc.) to invite experienced entrepreneurs, Industry elite to share the world's top business school case, a wealth of their own business stories, etc., to share the business and business management experience, in the exchange, the entrepreneur will enhance the creativity of students to give free guidance, while providing the latest entrepreneurs Industry Information.

There are more entrepreneurial class societies in Mainland Universities, most colleges and universities have set up entrepreneurial associations, such as Peking University Career Development Association, Tsinghua University students Entrepreneurs Association, the China Venture Association, Renmin University, Beijing University of Aeronautics and Astronautics Association of innovation and entrepreneurship. These entrepreneurial associations mainly carry out entrepreneurship education and training, provide business information services. through education and training activities of students to establish a correct view of entrepreneurship, talent concept, training entrepreneurial skills; invite entrepreneurship education instructors, entrepreneurs successful people, alumni or students of business practices are conducted members exchange and share experiences; expanding entrepreneurship information channels, extensive collect business projects and entrepreneurial information, providing information services; expand the service content, to carry out evaluation of entrepreneurship, business modeling, consulting assistance and guidance. Universities Venture inland communities are in larger quantities, but mostly in a spontaneous state, and in the lack of sound and effective working mechanism. the problem are the lack of professional management instructor with not high specialization, the lack of funding and space security, a lower level and not high quality of the activity, low level of socialization, a mere formality. Therefore it is difficult to hatching high quality entrepreneurial achievements and projects.

\subsection{Comparison of the Supportive Systematization}

Hong Kong University Entrepreneurship Education departments usually provide students with network support, financial assistance, incubation support and results of the system support. Hong Kong colleges and universities carry out systematic entrepreneurship education and training through the school professional entrepreneurial education institutions, through this bottom-up "professional model", make training more scientific, social, 
professional, specifically by the corresponding college responsible entrepreneurship research, entrepreneurship teaching, education Training, project incubation, technology transfer, fund support, competition organization and other services and consulting work.

Such as the Enterprise Development Institute in Hong Kong Polytechnic University, the Entrepreneurship Research Center in the Chinese University of Hong Kong, they actively integrate the internal and external resources providing the business services like conception, starting, promotion and other stages for the teachers and alumni who are aim at entrepreneurship. What's more they actively contact and integrate the resources of school Participants, out-of-school investors, entrepreneurial incubation centers, technical and business consultants in order to assist entrepreneurs who own the entrepreneurial concepts and ideas not only to find business partners and management teams but also to explore business opportunities. Advancing CUHK Entrepreneurship Hub has invited and cooperated the Cyberport, CoCoon, Hongkong Science Park, Hong Kong business angel network, Hongkong Productivity Council and other government and non-governmental organizations, hoping to meet the need of entrepreneurial team in different stages and industries. For example, the Cyberport provides the competition platform and financial support to those who have the entrepreneurial intentions and needs with the development plan aiming at digital industry company. CoCoon provides the Creative work space for entrepreneurs from different fields and opportunities to communicate with each other. The HKPC provides assistance and supports for the enterprises in the initial stage in terms of technology and market development. Hong Kong business angel network can help the start-up enterprise improve their entrepreneurship program and create chances to attract angel investment.

By 2015, the State Council issued the "Opinions on Deepening the Reform of Higher Education in innovation and entrepreneurship" and "the State Council on the highly innovative entrepreneurship and vigorously promote the public a number of policy measures" as to make the deepening the reform of the innovation and entrepreneurship education in Colleges and Universities as the breakthrough of promoting the comprehensive reform of Higher Education, and to set up advanced educational philosophy of innovation and entrepreneurship, for the whole, with the classification of teaching combined with profession, strengthening the practice, promoting overall development of students, and enhancing the quality of human capital, making efforts to create public entrepreneurship and innovation force. All levels of government, colleges and universities will gradually bring innovation and entrepreneurship education into important parts of education reform, attaches great importance to innovation and entrepreneurship education. By hosting entrepreneurial competitions, establishing the public entrepreneurial base, founding forum, launching Pioneer Park, improving the innovative entrepreneurship courses and other initiatives, they promote college students' innovation and entrepreneurship, to create a good atmosphere of innovation and entrepreneurship students, improve students' innovative spirit and entrepreneurial consciousness and innovation ability.

With the high social attention, the innovation and entrepreneurship education in mainland colleges and universities has entered a new phase. However, due to the late start and the weak pre-theoretical and practical foundation, innovation and entrepreneurship education in the mailand colleges and universities has still stay in the embryonic stage in the aspects of system, pattern, faculty, and evaluation mechanisms, which need advance, good planning and design, as learning from the advanced experience from Hong Kong Universities in innovation and entrepreneurship education, especially in how to give systematic support entrepreneurial associations, establish and improve support system. Currently, the venture communities in Mainland Universities are in a state of germination with excellent external environment and its own conditions. The focus is on how to develop those associations in system from proposing the project, to starting ground and financial support, and finally shaping project shape which is a systematic and in-depth project, needing further research and thinking. In summary, the entrepreneurial class community in mainland colleges and universities is a seed of innovation practice education. When promoting the innovation and entrepreneurship, we should cultivate the entrepreneurial communities directly.

\section{Analysis and Inspiration}

Affecting by the system, culture, history and other factors, there are a lot of differences in the student associations between mainland and Hong Kong, especially the innovative and entrepreneurship associations. But through the analysis of the Hong Kong University Students' associations, we can learn the advanced experience and systems to promote the healthy development of the Mainland college student associations when finding our problems. 


\subsection{To Invite Professional and Community as the Consultant for the Innovation and Entrepreneurship Communities}

The entrepreneurial associations in mainland has been established early and numerous in number, but the quality of the group, the operation mechanism and the development potential still need to be strengthened. The comprehensive analysis of the development of entrepreneurial associations in Mainland China is closely related to the lack or absence of the community guidance teachers. However, Colleges in Hong Kong attach great importance on professional guidance, such as the Chinese University of Hong Kong carrying out the "Peer Mentor Plan" to help students learn social experience. In this plan, the school chooses excellent alumni who are successful and famous in their fields as the peer mentor to help students improve the business projects and put it into practice. Hong Kong Polytechnic University established "Poly-preneur" plan which recruits over 500 successful entrepreneurs as the student mentors, using their valuable experience and social connection to provide practice suggestions for those innovative teams and students. In this way, in order to effectively improve the interior of college students into the industry level and quality, enhance innovation and entrepreneurship, it is necessary to serve as mentors for the university community to recruit entrepreneurial class industry experts and social entrepreneurs, through the "Dual Tutorial System" provides students with theoretical and Practice the dual guidance, and effectively play the role of college entrepreneurship community, and strive to hatch out the rich representative of the entrepreneurial achievements and cases.

\subsection{To Impel a More Scientific and Humane form Organization and Management Mechanisms}

Scientific management is the basis for the healthy functioning of society, humane societies is the source to maintain a healthy evolving of associations. The successful experience of Hong Kong's colleges and universities associations showed that only by constantly improving student organizations management system construction, clear management responsibilities and develop a standardized university community management methods can ensure the healthy development of community activities. Management system not only includes its own charter, management regulations, financial system, etc., should also include the management of the division of responsibilities, incentives, supervision mechanisms, rights and interests maintenance mechanism. At the same time, when adhering to the student-centered, respect for community self-management, self-service, under the premise of self-development, these associations should the activities that the majority of members actively require and respect the needs and requirement of most members. The activity project should be adopted by the whole members rather than decided by several student leaders and enforce the project.

\subsection{To Expand Sources of Funding, and Constantly Enhance the Degree of Social Functioning}

Funding is the basic guarantee for all activities of the community. The operation of the funding resources is much more mature in Hong Kong colleges and universities which has a clear effect. Compared to this situation, the funding resources is single and limited in mainland universities. Under the present circumstance, on the one hand, the schools should actively seek policy which can increase the intensity of financial support, and establish more forms of long-term, stable relations of cooperation between universities and enterprises, in this way to get relevant resources for student organizations. On the other hand the schools should encourage student organizations to actively take advantage of expertise and team strengths organize various social services, access to social and corporate sponsors, and actively carry out social operation. In addition, schools should encourage students to take the business community mode to "blood" approach change from blindly "blood", through the business park, the entrepreneurial base, and other entities, in order to gradually become not mainly depends on the administrative allocation of independent activity, conceited profit and loss of the organization to achieve community funding through a combination of free services and paid services to multiple sources.

4.4 Mainland Universities Should Play a Practical Role in the Integration of Resources, Innovation and Make Use of the College Characteristics in Effective Collaboration of Politic, Production and Research

College students innovation and entrepreneurship is a long-term and systematic engineering. It is necessary to integrate the internal and external resources for entrepreneurship and students to provide systematic services through a dedicated innovation and entrepreneurship education institutions co-ordination. The success of a venture project is closely related to the project's creative start-up, information consultation, project improvement, capital acquisition and achievement transformation. Only by closely cooperating with the government, the government, enterprises, universities and research institutions Contact, in order to really project landing, to the market. Take the ACEHUB project in the Chinese University of Hong Kong Center for Entrepreneurship in 2013 impel as an example, the main purpose of the project is to provide a concept, start-up, promotion of the various stages of business services for aspiring entrepreneurs CUHK University students and alumni, and actively associated with the integration of school participants outside investors, business incubation centers and technical 
and business consultants, all types of internal and external resources to assist persons with entrepreneurial concepts and ideas to find venture partners and management team, to develop business opportunities.

\section{Conclusion}

It is an inevitable requirement for the study of the situation of Hong Kong and the mainland students to innovate and innovate the community. It is an inevitable requirement for the study of youth work under the new situation in China, and tries to explore new ways and means to promote the work of the college community under the new situation. It is undoubtedly of great theoretical and practical significance to guide the work of community work in Chinese universities. The scientific analysis of the advanced management mechanism of Hong Kong, Macao and Taiwan will help us to better study the experience of the world's advanced university community management, enrich our college community management theory system, and prepare for the better integration into the trend of globalization of higher education. At the same time, hope that through comparative analysis, we can find their own problems and shortcomings, explore some new theories and new methods of reference, and promote the healthy development of China's higher education under the new situation.

\section{References}

China Education (10th ed.) (2006, April 26).

Li, D. (2003). Thinking about the work of the College Student Association. Nanjing Population Management Cadre College, 4.

Tang, C. H. (2003). On the role of university sports associations. School Party and ideological education, 6.

Tang, Y. J. (2008). Construction of College Students Sports Associations - Practice - investigation and exploring. Sport and Science, 1.

Wang, F. B. (2007). The new upgraded College Student Association Problems and Countermeasures. Xuzhou Education College, 4.

Xiao, R. (2005). Review of Sports Associations Research. Sport Science, 1.

Yang, F. J. (2005). Improving College Students 'Associations and College Students' Comprehensive Ability. Journal of Guangxi Youth Leaders College, 1.

Zhu, F. (2008). Situation of College Students' Organization in Hong Kong and the Mainland Universities functioning of inspiration. Journal of Guangxi Youth Leaders College, 2.

\section{Copyrights}

Copyright for this article is retained by the author(s), with first publication rights granted to the journal.

This is an open-access article distributed under the terms and conditions of the Creative Commons Attribution license (http://creativecommons.org/licenses/by/4.0/). 